\title{
Sustainable ecosystem governance under changing climate and land use: An introduction
}

\author{
Berit Hasler, Kari Hyytiäinen, Jens Christian Refsgaard, James C. R. Smart, \\ Karin Tonderski
}

\section{STATUS OF THE BALTIC SEA REGION}

Combatting eutrophication is currently a major challenge for policy makers in the Baltic Sea region, and it is likely to remain so in the decades to come. Although total nutrient loads to the Baltic Sea have recently declined, the gap between current loadings and those required to ensure the desired status is still substantial (Reusch et al. 2018). This Special Issue is dedicated to research that helps inform how the eutrophication challenge might best be addressed by improving our understanding of technological constraints, societal drivers of change, land uses, environmental policies, and innovative governance with stakeholder involvement. These issues are important for the current generation and those to come and are issues we must address in order to succeed in reducing nutrient loads to the desired levels to gradually achieve the desired good environmental status of the Baltic Sea.

Currently, we witness a new era of water policies across the entire Baltic Sea region. Our changing climate is impacting on precipitation and runoff, and is also the reason why new EU climate policies seek to tie carbon sinks more visibly to carbon sources. Both these aspects have repercussions for water policies. Thus, solving eutrophication challenges requires sharpening of existing policies and instruments, as well as creating new insights and governance approaches with broad stakeholder involvement in a changing environment. In order to design coherent water and climate policies, and target and implement those policies more efficiently, policy makers need to combine new insights regarding the inhabitants in the region, the catchments, and the Baltic Sea itself. Such insights can be expected from soil scientists, agronomists, hydrogeologists, marine ecologists, economists, and social and policy scientists. What is needed is on the one hand effectively targeted governance at appropriate spatial and temporal scales, adapted to differing interests and motivations of citizens living around the Baltic Sea, and on the other hand fine tuning and co-designing of policies at local, national, Baltic Sea regional and EU level. This Special Issue brings together recent research from four BONUSfunded projects-BONUS BALTICAPP, BONUS GO4BALTIC, BONUS MIRACLE and BONUS SOILS2SEA - that comprised part of the 'Viable Ecosystem' and 'Sustainable Ecosystem Services' BONUS research programmes. The projects addressed these common concerns through somewhat different, but inter-related, themes.

Key messages emphasized and discussed in the research papers of this Special Issue are summarized under four interlinked themes: Scenarios for the future, Policies and ecosystem services in water governance, Novel approaches for managing nutrients, and Advanced modelling from field level to the entire Baltic Sea region.

\section{SCENARIOS FOR THE FUTURE}

Several studies adopt a long-term perspective in studying plausible pathways concerning how nutrient loading, the policy debate and the environmental state of the Baltic Sea may evolve in response to climate change and socioeconomic drivers.

- Scenarios can help society shape and adapt to an uncertain future (Meier et al. 2019; Bauer et al. 2019). Different kinds of scenario analyses and methods to visualize outcomes under different scenarios can be useful for informing debate about policy adjustments (Jansson et al. 2019), as well as for efficient 
communication between scientists, local and regional stakeholders and decision makers (Neset et al. 2019).

- One particular focus of BONUS-funded research is that nutrient loads are driven by climate change as well as by changes in land use, agricultural practice and other socioeconomic developments. This has been studied using four climate model projections for 2041-2060 in combination with Shared Socioeconomic Pathways (for socioeconomic development) in two catchments in Denmark and Poland (Olesen et al. 2019), and for the Baltic Sea drainage basin as a whole (Bartosova et al. 2019). Results showed that climate change in itself will lead to increased nutrient loads, but also that changes in socioeconomic drivers can have larger impacts than climate change. The results from the two small catchments using two different impact models suggest large uncertainties regarding future nitrate leaching due to model structural uncertainties. This indicates that an ensemble approach, as used frequently for climate projections, may also be required for impact modelling.

- Scenarios for nutrient loads in a future climate suggest large uncertainties and spatial differences within the region (Bartosova et al. 2019; Olesen et al. 2019). When moving towards more adaptive policy frameworks, those uncertainties and spatial differences should be acknowledged from the outset.

- According to physical-biogeochemical model simulations, full implementation of the current policy agreements would allow the marine ecosystem to gradually evolve towards the desired 'good environmental status' in most basins of the Baltic Sea (Meier et al. 2019). Coupled environmental-climate scenario simulations for combinations of greenhouse gas emissions and nutrient load scenarios indicate the sets of situations under which a good environmental state can be reached. However, due to global climate change, extreme events such as tropical nights, record-breaking sea surface temperatures and occasional but massive cyanobacteria blooms are expected to become more frequent.

- Linking modelling frameworks that focus on societal and natural processes relevant to the studied management problem helps us to build a richer picture about the consequences of global futures at regional, local and ecosystem scales. Bauer et al. (2019) demonstrate this by using outputs from a physical-biogeochemical model, driven by societal developments, as inputs to a spatially explicit food web model. They studied fish species composition, habitat quality and the future prospects of fisheries under alternative regionally downscaled socioeconomic and climate futures. Their results demonstrate remarkable variation in performance metrics across alternative extreme scenarios.
- Scenario results can provide useful support for policy development when associated with participatory processes. Neset et al. (2019) studied how results from hydrological models could be used in participatory processes with expert stakeholders in four case areas around the Baltic Sea, as well as in cross-case discussions. They identified a number of barriers to, and opportunities for, using scenario modelling to support good governance among expert stakeholders. For example, in dialogues that include complex tools, such as the HYPE model, the presence of experts in meetings is essential for providing additional information, explanations and alternative approaches to help overcome barriers in the understanding of complex concepts (e.g. uncertainties), and to foster more informed interpretation of results. Neset et al. (2019) also concluded that the use of a tool linking current choices with future effects requires a dialogue design that allows sufficient time for stakeholder-tool interaction, reflection and discussions of results. Under such conditions, scenario results can potentially contribute to empowerment, legitimacy, equity and-ultimatelyimproved and inclusive water governance. The importance of trust and legitimacy was also emphasized by Zilans et al. (2019) who synthesized key factors of success from existing examples of innovative policy instruments to identify barriers and opportunities for the implementation of policy innovations in different institutional settings across the Baltic Sea region.

\section{POLICIES AND ECOSYSTEM SERVICES IN WATER GOVERNANCE WITHIN THE BALTIC SEA REGION}

Coherent implementation of policies to reduce eutrophication and climate change, integration of ecosystem services approaches in coherent management models, and mechanisms for improving policy implementation have been analysed in a number of studies.

- Progress of agri-environmental policies is important in the Baltic Sea region, as the public and private costs of nutrient abatement are high (Hasler et al. 2019; Jansson et al. 2019; Lötjönen and Ollikainen 2019; Ollikainen et al. 2019).

- The costs of nutrient abatement measures are often high, but the value of additional local benefits may outweigh these costs. Policies have also proved successful in stimulating technological development and innovation (Ollikainen et al. 2019).

- There has been a long-lasting debate regarding whether further differentiation of measures and contract 
obligations will improve uptake and effectiveness of agri-environmental subsidy schemes offered as part of the EU's Rural Development Programme. The results in Hasler et al. (2019) indicate that farmers' preferences for different attributes of agri-incentive schemes vary substantially between farm types within five countries around the Baltic Sea, as well as between countries. The results indeed suggest that differentiation of contract obligations and payment levels will improve the uptake of agri-environmental schemes.

- Habitat values, recreation and enjoyment of landscapes are among the most important cultural ecosystem services provided by the Baltic Sea according to a new survey conducted in three countries: Germany, Latvia and Finland (Ahtiainen et al. 2019). Cultural ecosystem services are non-material and non-extractive outputs that affect the physical and mental states of people.

- Jansson et al. (2019) linked the Capri model to a nitrogen leaching model and the BALTSEM marine model for the Baltic Sea, thereby simulating the results of changes in the agricultural sector on the Sea's environmental status. This integrated model framework was used to study the likely outcome of replacing the current greening obligations in the EU's Common Agricultural Policy (the CAP) with technological improvement of the utilization of manure (enhanced storage capacity and improved manure application techniques). Results indicate that these changes will lead to significant variation in the resulting effects in different Baltic Sea basins.

- The coordination and interconnections between different sectors and policy instruments (e.g. the CAP, Rural Development Programs, the Water Framework Directive, the Floods Directive, climate policies) need to be strengthened (Ollikainen et al. 2019; Lötjönen and Ollikainen 2019). Lötjönen and Ollikainen (2019) examine the most effective policies for reducing both nutrient and climate emissions and show that coherent implementation of nutrient and climate policies reduce costs. Using the ecosystem services framework can facilitate the design of measures with multiple objectives (Zilans et al. 2019).

- A better coherence between local and regional stakeholders may be achieved by strengthening the mandate of local stakeholder groups currently involved in water and nutrient governance. Co-governance and participatory bottom-up approaches boost innovation and enable better usage of otherwise hidden information about local conditions, and thereby increase involvement (Zilans et al. 2019). For example, a bottom-up costbenefit approach is beneficial for generating and assessing strategies which represent the preferences of local stakeholders when addressing a given problem (Carolus et al. 2018). The knowledge gained can be used to, for example, adjust top-down policies or improve support or tax mechanisms.

- Ollikainen et al. (2019) summarize the main problems with existing policy approaches that can explain the gap between the desired environmental policy targets and the achieved environmental status of the Baltic Sea. With these insights, changes are proposed through policy innovation, increased use of market-based instruments and targeted regulation to reduce discrepancies between achieved and desired outcomes.

\section{NOVEL APPROACHES FOR MANAGING NUTRIENTS IN THE BALTIC SEA REGION}

Methods to apply more targeted regulation are novel and key to managing nutrients effectively and efficiently. A number of studies address the potential of targeting and differentiating nutrient management.

- There is a need to improve nitrogen use efficiency in the Baltic Sea region in order to reduce nutrient loads and at the same time maintain or even increase agricultural crop yields (Olesen et al. 2019; Jansson et al. 2019).

- Farmers are skilled problem solvers, but they need the right incentives and a governance framework that provides the possibility for flexible adjustments when including environmental management into farm business decision making (Refsgaard et al. 2019; Hasler et al. 2019). Implementation of spatially differentiated regulations and incentives can reduce nutrient loadings, but new governance concepts would have to be implemented to enact this (Refsgaard et al. 2019; Lötjönen and Ollikainen 2019; Ollikainen et al. 2019). Building on results from other studies (e.g. Jakobsen et al. 2019; Olesen et al. 2019; Bartosova et al. 2019), Refsgaard et al. (2019) analysed the potential benefits, as well as scientific and governance challenges, of a spatially differentiated regulation strategy. Such a spatially differentiated strategy targets mitigation measures towards areas where nature's own capacity for nutrient removal is low, increasing cost-effectiveness in comparison to traditional uniform regulation.

- One size does not fit all; the complex environmental conditions and diverse societies around the Baltic Sea region require a variety of policy instruments. Water quality trading, spatially targeted regulations and performance-based measures have a high potential to reduce the cost of nutrient load reductions. Policy 
barriers for their use should be removed (Refsgaard et al. 2019; Ollikainen et al. 2019).

- Demonstration examples of various cooperation schemes, such as hybrid payments with both public and private funding, should be implemented in the Baltic Sea region (Zilans et al. 2019).

\section{ADVANCED MODELLING FROM FIELD LEVEL TO THE ENTIRE BALTIC SEA REGION}

Development of advanced models at different spatial scales can aid and inform policy implementation by supporting selection of the most effective and also cost-effective approaches.

- Field studies generating new process knowledge are typically performed at small scale on fields, hill slopes or small catchments (Jakobsen et al. 2019; Olesen et al. 2019), while impact analyses of regional Baltic Sea policies require model simulations for the entire Baltic Sea drainage basin (Bartosova et al. 2019). Bartosova et al. (2019) have improved the HYPE model of the Baltic Sea drainage basin by implementing a methodology proposed by Refsgaard et al. (2019) for upscaling local-scale modelling results on targeted measures at field scale to Baltic Sea drainage basin scale.

- In many glacial till areas, a major proportion of nitrate leaching from agricultural fields is removed by geochemical reduction in groundwater systems (Højberg et al. 2017). Jakobsen et al. (2019) have performed detailed field studies and PHREEQC modelling to assess how reactive nitrogen behaves at a Danish agricultural field site. The study documents how complex processes remove nitrogen on its path from the root zone through the saturated zone towards streams and receiving waters.

- Adaptive and flexible policies require reliable models that have credibility among stakeholders (Jakobsen et al. 2019). To gain the necessary credibility, model predictive uncertainties should be communicated effectively (c.f. Neset et al. 2019). To assess the uncertainty when modelling impacts of climate change and future land use, it is recommended to use several models in an ensemble modelling approach rather than relying on just one model (Olesen et al. 2019; Jansson et al. 2019).

- Models can inform policy implementation. Models can also be used to further develop the science-policy interface. Here, the most appropriate models are needed, not necessarily the most detailed (Refsgaard et al. 2019). Linking agricultural sector modelling to ecological models in the Baltic Sea, as in Jansson et al. (2019), also provides results that can help to improve agricultural and nutrient abatement policies in the Baltic Sea region.

\section{CONCLUSION}

Focusing on these themes, this Special Issue addresses current knowledge about nutrient loading of the Baltic Sea and its consequences, plausible future developments, and ecosystem services, as well as suggesting ways forward regarding stakeholder involvement, design of policy instruments and governance structures to mitigate the problem.

The Special Issue includes 12 articles in the fields of agronomy, hydrology, marine ecology, economics and policy sciences. The results were presented and discussed at the 3rd BONUS Symposium: "Sustainable Ecosystem Governance under Changing Climate and Land Use in the Baltic Sea Region" held in the European Solidarity Centre in Gdańsk, 14-16 March, 2018. The Symposium brought together scientists, policymakers, NGOs, representatives from the private sector and authorities from various levels. Findings from these research projects will be of interest in any settings-elsewhere in Europe and globally-where water quality management is confronted by challenges driven by socioeconomic developments in combination with climate change.

Acknowledgements The work in the projects BONUS BALTICAPP, BONUS GO4BALTIC, BONUS MIRACLE and BONUS SOILS2SEA is supported by BONUS (Art 185), funded jointly by the EU and national funding institutions in Denmark (Innovation Fund Denmark), Estonia (Estonian Research Council ETAG), Germany (Forschungszentrum Jülich $\mathrm{GmbH}$ ), Latvia (Latvian Ministry of Education and Science), Finland (Academy of Finland), Poland (NCBR) and Sweden (Naturvårdsverket, FORMAS), and Russia (Russian Foundation for Basic Research).

\section{REFERENCES}

Ahtiainen, H., E. Liski, E. Pouta, K. Soini, C. Bertram, K. Rehdanz, K. Pakalniete, and J. Meyerhof. 2019. Cultural ecosystem services provided by the Baltic Sea marine environment. Ambio. https://doi.org/10.1007/s13280-019-01239-1.

Bartosova, A., R. Capell, J.E. Olesen, M. Jabloun, J.C. Refsgaard, C. Donnelly, K. Hyytiäinen, S. Pihlainen, et al. 2019. Future socioeconomic conditions may have a larger impact than climate change on nutrient loads to the Baltic Sea. Ambio. https://doi.org/ 10.1007/s13280-019-01243-5.

Bauer, B., B.G. Gustafsson, K. Hyytiäinen, H.E.M. Meier, B. MüllerKarulis, S. Saraiva, and M.T. Tomczak. 2019. Food web and fisheries in the future Baltic Sea. Ambio. https://doi.org/10.1007/ s13280-019-01229-3.

Carolus, J.F., N. Hanley, S.B. Olsen, and S.M. Pedersen. 2018. A bottom-up approach to environmental cost-benefit analysis. 
Ecological Economics 152: 282-295. https://doi.org/10.1016/j. ecolecon.2018.06.009.

Hasler, B., M. Czajkowski, K. Elofsson, L.B. Hansen, M.T. Konrad, H.Ø. Nielsen, O. Niskanen, T. Nõmmann, et al. 2019. Farmers' preferences for nutrient and climate-related agri-environmental schemes: A cross-country comparison. Ambio. https://doi.org/10. 1007/s13280-019-01242-6.

Højberg, A.L., A.L. Hansen, P. Wachniew, A. Zurek, S. Virtanen, J. Arustiene, J. Strömqvist, K. Rankinen, et al. 2017. Review and assessment of nitrate reduction in groundwater in the Baltic Sea Basin. Journal of Hydrology: Regional Studies 12: 50-68. https://doi.org/10.1016/j.ejrh.2017.04.001.

Jakobsen, R., A.L. Hansen, K. Hinsby, D. Postma, and J.C. Refsgaard. 2019. Reactive nitrogen in a clay till hill slope field system. Ambio. https://doi.org/10.1007/s13280-019-01228-4.

Jansson, T., H.E. Andersen, B. Hasler, L. Höglind, and B.G. Gustafsson. 2019. Can investments in manure technology reduce nutrient leakage to the Baltic Sea? Ambio. https://doi.org/10. 1007/s13280-019-01251-5.

Lötjönen, S., and M. Ollikainen. 2019. Multiple-pollutant costefficiency: Coherent water and climate policy for agriculture. Ambio. https://doi.org/10.1007/s13280-019-01257-z.

Meier, H.E.M., Dieterich, K. Eilola, M. Gröger, A. Höglund, H. Radtke, S. Saraiva, and I. Wåhlström. 2019. Future projections of record-breaking sea surface temperature and cyanobacteria bloom events in the Baltic Sea. Ambio. https://doi.org/10.1007/ s13280-019-01235-5.

Neset, T.-S., J. Wilk, C. Navarra, R. Capell, and A. Bartosova. 2019. Visualization-supported dialogues in the Baltic Sea Region. Ambio. https://doi.org/10.1007/s13280-019-01250-6.

Olesen, J.E., C.D. Børgesen, F. Hashemi, M. Jabloun, D. BarMichalczyk, P. Wachniew, A.J. Zurek, A. Bartosova, et al. 2019. Nitrate leaching losses from two Baltic Sea catchments under scenarios of changes in land use, land management and climate. Ambio. https://doi.org/10.1007/s13280-019-01254-2.

Ollikainen, M., B. Hasler, K. Elofsson, A. Iho, H.E. Andersen, M. Czajkowski, and K. Peterson. 2019. Towards the Baltic Sea Socioeconomic Action Plan. Ambio. https://doi.org/10.1007/ s13280-019-01264-0.

Refsgaard, J.C., A.L. Hansen, A.L. Højberg, J.E. Olesen, F. Hashemi, P. Wachniew, A. Wörman, A. Bartosova, et al. 2019. Spatially differentiated regulation: $C a n$ it save the Baltic Sea from excessive N-loads? Ambio. https://doi.org/10.1007/s13280-01901195-w.

Reusch, T.B.H., J. Dierking, H.C. Andersson, E. Bonsdorff, J. Carstensen, M. Casini, M. Czajkowski, B. Hasler, et al. 2018. The Baltic Sea as a time machine for the future coastal ocean. Science Advances 4. http://dx.doi.org/10.1126/sciadv.aar8195.

Zilans, A., G. Schwarz, K. Veidemane, M. Osbeck, A. Tonderski, and O. Olsson. 2019. Enabling policy innovations promoting multiple ecosystem benefits: Lessons learnt from case studies in the
Baltic Sea Region. Water Policy 21 (3): 546-564. https://doi.org/ 10.2166/wp.2019.054.

Publisher's Note Springer Nature remains neutral with regard to jurisdictional claims in published maps and institutional affiliations.

\section{AUTHOR BIOGRAPHIES}

Berit Hasler $(\square)$ is a Senior Researcher in Environmental Economics at Aarhus University, Department of Environmental Science. She is head of the Social science and geography unit at the department. Her research has specific focus on regulating agricultural pollution and water quality. She coordinated the BONUS GO4BALTIC project.

Address: Department of Environmental Science, Aarhus University, Aarhus, Denmark.

e-mail: bh@envs.au.dk

Kari Hyytiäinen is a Professor and Vice Dean at the Faculty of Agriculture and Forestry, University of Helsinki. His research addresses the economics of marine protection, with a special focus on the Baltic Sea. He coordinated the BONUS BALTICAPP project.

Address: Faculty of Agriculture and Forestry, University of Helsinki, Helsinki, Denmark.

Jens Christian Refsgaard is a Professor Emeritus at the Department of Hydrology, Geological Survey of Denmark and Greenland. His research focuses on impacts of human interaction, such as changes in climate, land use and agricultural practices, on water resources. He coordinated the BONUS SOILS2SEA project.

Address: Department of Hydrology, Geological Survey of Denmark and Greenland, Copenhagen, Denmark.

James C. R. Smart is an Associate Professor and an Environmental Economist in the School of Environment and Science and the Australian Rivers Institute at Griffith University, Brisbane, Australia. His research addresses the economics of water quality management, particularly with regard to sediment and nutrient runoff in catchments, lakes and coastal waters.

Address: School of Environment and Science and the Australian Rivers Institute at Griffith University, Brisbane, Australia.

Karin Tonderski is an Associate Professor at the Departments Physics, Chemistry and Biology and Management and Engineering, Linköping University. With a background in research on wetlands for water pollution control, she is now focused on collaborative system studies of water and nutrient management. She coordinated the BONUS MIRACLE project.

Address: Departments Physics, Chemistry and Biology and Management and Engineering, Linköping University, Linköping, Denmark. 